\title{
Cohort differences in 3-year adaptation to health problems among Dutch middle-aged, 1992-1995 and 2002-2005
}

\author{
Dorly J. H. Deeg • Martijn Huisman
}

Published online: 14 August 2010

(c) The Author(s) 2010. This article is published with open access at Springerlink.com

\begin{abstract}
Midlife is a period during which ageing-related health problems first emerge. In view of increasing life expectancy, it is of great importance that people in midlife adapt to possible health problems, to be able to lead productive and engaged lives as long as possible. It may be expected that given the better circumstances in which more recent cohorts grew up, they are better equipped to adapt to health problems than earlier cohorts. This study addresses the question if the way people in midlife adapt to health problems is or is not improving in the Netherlands. The study is based on the nationally representative 1992-1993 and 2002-2003 cohorts of the Longitudinal Aging Study Amsterdam (ages 55-64 years), with follow-up cycles in 1995-1996 $(n=811)$ and 2005-2006 $(n=829)$, respectively. Mastery is considered as a measure of adaptation, and 3-year change in mastery is compared in subjects without and with health problems at baseline. A rise was observed in the prevalence of diabetes, chronic lung disease, arthritis, subthreshold depression, and disability. Subjects without health problems in the recent cohort had
\end{abstract}

Handling editor: S. L. Willis, M. Martin, C. Röcke, H.-W. Wahl.

D. J. H. Deeg · M. Huisman

VU University Medical Centre/LASA, EMGO Institute for Health and Care Research, Van der Boechorststraat 7, 1081 BT Amsterdam, The Netherlands

D. J. H. Deeg $(\varangle) \cdot$ M. Huisman

Department of Psychiatry, VU University Medical

Centre/LASA, Van der Boechorststraat 7,

1081 BT Amsterdam, The Netherlands

e-mail: djh.deeg@vumc.nl

M. Huisman

Department of Sociology, VU University, Amsterdam,

The Netherlands better mastery than their counterparts in the early cohort. Regardless of cohort membership, mastery declined over 3 years for those with subthreshold depression, mild disability, chronic lung disease, and stroke. In the recent cohort only, mastery declined for those with cognitive impairment, but improved for those with heart disease. These findings do not support the expectation that recent cohorts are better equipped to deal with health problems for conditions other than heart disease.

Keywords Midlife $\cdot$ Sense of mastery $\cdot$ Chronic conditions - Depression - Cognitive impairment . Cohort differences

\section{Introduction}

Midlife is a period during which the first ageing-related health problems emerge, including chronic somatic or mental conditions. Having a chronic condition may affect psychosocial resources such as self-worth and sense of mastery. Sense of mastery is considered a fundamental marker of successful ageing (Rowe and Kahn 1997). It is defined as the extent to which one views one's life as within one's control as opposed to ruled by chance or other persons (Pearlin and Schooler 1978).

When faced with a chronic condition, individuals may undergo medical treatment, experience uncertainty about the prognosis and even threats to life, feel socially stigmatised, develop physical limitations, and become dependent on the help of others. In this situation, feelings of self-worth, and control over one's life may be threatened. A high level of psychosocial resources may have a beneficial influence on the adaptation to chronic health problems. However, lack of psychosocial resources may influence adaptation 
negatively, e.g. because individuals may take less responsibility for their health, may be less likely to engage in health protective behaviours, and may not be able to adequately indicate their needs to the right people (Rodin and Timko 1991; Wolinsky et al. 2003). This in turn may further deteriorate feelings of mastery.

A host of studies show the beneficial effect of a high sense of mastery-or perceived control—on physical and mental health (e.g. Bisschop et al. 2004; Chipperfield et al. 2004; Femia et al. 1997; Gadalla 2009; Mackenbach et al. 2001; Wallhagen et al. 1994). Fewer studies have addressed the effect of health problems on sense of mastery (Cairney and Krause 2008; Jang et al. 2009; Menec et al. 1999; Slagsvold and Sorensen 2008; Wolinsky et al. 2003). The latter studies show that sense of mastery is negatively affected by both mental and physical health problems, with more studies focusing on mental health. When physical health is addressed, none of these studies distinguish between various conditions in their effect on the sense of mastery. Nevertheless, it may be expected that specific conditions do not have the same effect.

Specific conditions differ according to disease characteristics, such as functional incapacitation, social impact, controllability and predictability of the course, and fatality (Moos and Schaeffer 1984; Rolland 1987). These differences in characteristics make it likely that the effects on the sense of mastery differ across diseases. Comparing the influences of different diseases over time may help to identify the influence of disease characteristics. It should be noted, however, that disease-related changes in the sense of mastery may result from characteristics of the disease itself, from concomitant diseases (comorbidity), or from consequences of the disease such as disability. The first objective of this study is to examine the longitudinal effect of several chronic conditions on sense of mastery, thereby accounting for the effect of comorbidity and disability.

In view of increasing life expectancy, it is of great importance that people who fall ill at midlife adapt to their health problems, to be able to lead productive and engaged lives as long as possible. Recent cohorts of middle-aged people may be better equipped to do this than earlier cohorts, because they have grown up in more prosperous circumstances. On average, they have had more years of education, and have experienced better welfare conditions (Crimmins 2004; Broese van Groenou and Deeg 2010). Therefore, during their life course they may have developed a better sense of mastery than previous cohorts. On the other hand, the recent emphasis on empowerment and successful ageing may turn against those who already at midlife are struck with ageing-related diseases. Were ageing-related diseases considered inevitable and expected in previous cohorts, they may be unexpected in recent cohorts of middle-aged persons. The onset of ill health may confront these individuals with their inability to alter unwanted circumstances in their lives (Pearlin et al. 1981), and this may affect their sense of mastery more than it did members of earlier cohorts. This study's second objective, then, is to examine if sense of mastery of people in midlife in relation to health problems has or has not improved in more recent cohorts.

\section{Methods}

\section{Sample}

The current study is part of the Longitudinal Aging Study Amsterdam (LASA), an ongoing multi-disciplinary study on predictors and consequences of changes in well-being and autonomy in the older population (Deeg et al. 1993). The sampling and procedures adopted to achieve the baseline sample and the response rates at baseline and follow-up have been described in detail in previous publications (Deeg et al. 2002). What follows here is a summary of the main design characteristics.

At baseline, the random, nationally representative, age and sex stratified sample consisted of 3107 older adults (55-85 years). The sample was drawn from the population registries of 11 municipalities in three regions of the Netherlands: the west, the north-east, and the south. The overall response rate was $62.3 \%$. Data were gathered in face to face interviews at baseline (1992-1993) and in subsequent cycles 3 years apart.

Respondents were interviewed in their homes by specially trained and intensively supervised interviewers. Informed consent was obtained prior to the study, in accordance with legal requirements in the Netherlands. The research was carried out in compliance with the Helsinki declaration, and was approved by the ethics committee of the VU University Medical Centre.

In 2002, a new cohort aged 55-64 years $(N=1002)$ was selected from the populations registers of the same municipalities, with a response rate of $57.1 \%$. This cohort is referred to as the 'recent' cohort. For the present study, those with ages 55-64 were selected from the 1992-1993 cohort, referred to as the 'early' cohort. The consecutive cohorts thus have the same age range with an interval of 10 years.

Three-year follow-up cycles of the cohorts took place in 1995-1996 and 2005-2006, respectively. Drop-out rates were 8.3 and $9.4 \%$ in the early and recent cohorts, resulting in follow-up sample sizes of 886 and 907, respectively. Although recent cohort's mortality was lower (2.3 vs. 3.7\% in the early cohort), their refusal rate was higher (7.1 vs. $4.5 \%$ in the early cohort). Due to missing values on the outcome variable, mastery, the sample sizes included in 
this study were 811 and 829 for the early and recent cohorts, respectively.

\section{Measures}

\section{Mastery}

Sense of mastery is defined as the extent to which one views one's life as within one's control as opposed to ruled by chance or other persons (Pearlin and Schooler 1978). Pearlin and Schooler proposed a 7-item scale to measure this concept, which proved to have validity (Pearlin et al. 1981). In our study, this concept was assessed using a fiveitem version of this scale consisting of only negative items, because this was found to have better reliability (Gadalla 2009). An example of an item is: 'I have little control over the things that happen to me'. The scale ranged from 5 to 25, with higher score indicating more mastery. In the current study sample, its reliability (Cronbach's alpha) was 0.76. Change in mastery was calculated as the difference in scores between follow-up $\left(\mathrm{T}_{2}\right)$ and baseline $\left(\mathrm{T}_{1}\right)$. This new variable had mean 0 , standard deviation 3.1, and 5 th and 95th percentiles at -5 and +5 , respectively.

\section{Health problems}

All health problems were assessed at baseline.

The presence of chronic diseases was assessed by asking the participants whether they had any of the following diseases: heart disease, peripheral artery disease, stroke, diabetes, chronic obstructive lung disease, cancer or arthritis. When compared to records of the participants' general practitioners, the agreement between self-reports and medical records proved satisfactory (Kriegsman et al. 1996). The number of chronic diseases was calculated to indicate multimorbidity. The Mini Mental State Examination (MMSE) was used to assess cognitive status (Folstein et al. 1975). The score ranges between 0 and 30 and a score of 23 or below is used to indicate cognitive impairment (Tombaugh and McIntyre 1992). The Center for Epidemiological Studies Depression Scale (CES-D) was used to measure depressive symptoms (Radloff 1977; Beekman et al. 1997). The scores range from 0 to 60. A score of 16 and higher is interpreted as indicative of subthreshold depression. Disability was assessed by asking respondents whether health problems limited their daily activities for longer than 3 months, using a 3-point scale coded as $0=$ no, $1=$ mildly, $2=$ severely (Van Oyen et al. 2006).

\section{Covariates}

Covariates included age, gender, level of education (elementary schooling or less, secondary schooling, and higher education), gainful employment, and partner status (having no partner versus having a partner within or outside the household) at baseline.

\section{Statistical analyses}

In order to examine baseline characteristics of the two cohorts, possible sampling differences in the age-sex distribution were accounted for by applying sample weights to the recent cohort, so that its age-sex distribution became the same as in the early cohort. The weights were calculated as the ratio of the expected and the observed number of subjects in each single age-sex category, where the expected number was based on the early cohort. Baseline characteristics of the early and recent cohorts were then compared using the chi-square test for categorical and the $t$-test for continuous variables. A further descriptive step was to examine correlates of baseline mastery in a multivariable linear regression model.

In order to examine change in mastery in both cohorts, the correlation of mastery scores at baseline and follow-up were compared between the two cohorts. In addition, a possible cohort difference in change in mastery was examined using a general linear model for repeated measurements with cohort number as the factor.

Multivariable linear regression models examined change in mastery, calculated as the difference score of follow-up, $\mathrm{T}_{2}$, minus baseline, $\mathrm{T}_{1}$, and included baseline mastery, age and sex. Other potential explanatory factors for change in mastery were examined in order to determine which should be included in future models of specific conditions. This should guarantee optimally parsimonious models, in view of the low prevalence of some conditions. To examine the first research question, for each specific condition as observed at baseline, its association with change in mastery was examined in a model adjusted for relevant covariates, including baseline mastery. Unstandardised regression coefficients (B's) are reported, which can be interpreted as the difference in change in mastery between those with and those without the health problems, all else being equal. Except for mastery itself, then, for all variables only baseline assessments are included in our regression models. The rationale for this is that inclusion of only their baseline assessment allows conclusions about the consequences of having a chronic condition, in this case experiencing a change in mastery. Thus, the problem of disentangling cause and effect is reduced, because the chronological sequence is clear.

To address the second research question, in each model it was examined if adding an interaction term of condition * cohort improved the model. If the interaction term was significant $(p<0.10)$, cohort-stratified analyses were run to compare the associations of the condition with change in mastery. 


\section{Results}

Sample attrition

From the combined baseline samples of the two cohorts, 328 subjects $(16.7 \%)$ did not have complete data at followup. As mortality is a natural reason for attrition and does not affect generalisability of the findings, those who had complete data were compared to the survivors who dropped out because of refusal or impossibility to establish contact. In comparison to surviving drop-outs, continuing participants were more often highly educated, had more often a partner, had less often subthreshold depression, cognitive impairment or severe disability and also had a higher baseline mastery. However, they were no different in terms of age, gender, gainful employment, and somatic conditions.
Baseline characteristics: cohort differences

From a comparison between continuing participants from the early and recent cohorts (Table 1), striking differences were seen in the higher education and labour market participation of the recent cohort. In 10 years time, having only elementary schooling in 55-64-year-olds had decreased by $12.5 \%$ points to $18.6 \%$, and higher schooling had increased by $7.5 \%$ points to $25.5 \%$. Gainful employment rose by $14.6 \%$ points to $43.9 \%$. Less favourable were the increases shown in poor health: significantly more 55-64-year-olds had two or more chronic somatic diseases in the recent cohort (from 14.2 up to $16.3 \%$ ); regarding the separate diseases, the prevalence of diabetes and arthritis showed significant increases; and both mild and severe chronic disability (lasting at least 3 months) rose significantly from 14.2 and $6.8 \%$ up to 20.7 and $9.5 \%$, respectively. Also,

Table 1 Baseline characteristics of early and recent cohorts, 1992-1993 and 2002-2003, continuing participants Longitudinal Aging Study Amsterdam

\begin{tabular}{|c|c|c|c|c|}
\hline & $\begin{array}{l}\text { Cohort } 1928-1937 \\
\text { in } 1992-1993 \\
(N=811)\end{array}$ & $\begin{array}{l}\text { Cohort } 1938-1947 \\
\text { in } 2002-2003^{\#} \\
(N=829)\end{array}$ & $t$-test & $\begin{array}{l}\text { Chi-square } \\
\text { test (df) }\end{array}$ \\
\hline Age (M, sd) & $60.1(2.8)$ & $59.9(2.9)$ & 1.78 & \\
\hline Gender ( $\%$ female $)$ & 52.9 & 52.3 & & $0.07(1)$ \\
\hline Education $(\%)$ & & & & $38.55(2)$ \\
\hline Low & 31.1 & 18.6 & & \\
\hline Middle & 50.9 & 55.9 & & \\
\hline High & 18.0 & $25.5 * *$ & & \\
\hline Partner (\%) & 83.0 & 85.1 & & $1.34(1)$ \\
\hline Paid job (\%) & 29.3 & $43.9 * *$ & & $38.08(1)$ \\
\hline Somatic diseases $(\%)$ & & & & $8.72(2)$ \\
\hline One & 33.3 & 38.7 & & \\
\hline Two or more & 14.2 & $16.3 *$ & & \\
\hline \multicolumn{5}{|l|}{ Specific diseases $(\%)$} \\
\hline Heart disease & 13.2 & 11.0 & & $1.88(1)$ \\
\hline Peripheral artery disease & 6.1 & 5.1 & & $0.72(1)$ \\
\hline Stroke & 1.2 & 2.5 & & $3.53(1)$ \\
\hline Diabetes & 3.4 & $6.5^{*}$ & & $8.33(1)$ \\
\hline Chronic lung disease & 7.2 & 9.8 & & $3.48(1)$ \\
\hline Cancer & 6.0 & 8.0 & & $2.58(1)$ \\
\hline Arthritis & 28.6 & $34.1^{*}$ & & $5.56(1)$ \\
\hline Subthreshold depression (\%) & 10.5 & $13.4^{+}$ & & $3.32(1)$ \\
\hline Cognitive impairment $(\%)$ & 7.2 & 8.8 & & $1.42(1)$ \\
\hline Disability longer than 3 months (\%) & & & & $18.35(2)$ \\
\hline Mild & 14.2 & 20.7 & & \\
\hline Severe & 6.8 & $9.5^{* *}$ & & \\
\hline Mastery $(M, s d)$ & $18.1(3.3)$ & $18.2(3.5)$ & -1.01 & \\
\hline
\end{tabular}

\# Data of 2002-2003 weighted to age-sex distribution of 1992-1993

Significant cohort difference: ${ }^{+} p<0.10, * p<0.05, * * p<0.001$ 
subthreshold depression showed an almost significant increase. No significant changes between the cohorts were seen in partner status and in cognitive functioning. The same was true for baseline mastery.

\section{Correlates of mastery}

In the combined baseline sample, socio-demographic and health variables explained $16.1 \% \quad(F(\mathrm{df})=25.7(12)$, $p<0.001$ ) of the variance in baseline mastery (Table 2, first two columns). In this adjusted model, the effect of cohort on baseline mastery was just significant $(p=0.05)$, indicating that the recent cohort had a higher sense of mastery than the early cohort, all else being equal. More detailed analysis showed that there were suppressor effects for the health variables, and in particular for subthreshold depression (data not shown). This can be understood as follows: when the higher prevalence of health problems in the recent cohort is accounted for, this cohort's mastery is higher than the earlier cohort's. In other words, among the healthy, mastery is higher in the recent cohort.

Regarding the socio-demographic variables, age and education were not significantly associated, but having a partner and having paid work were positively associated with sense of mastery. Among the health variables, subthreshold depression and cognitive impairment showed the strongest associations, followed by mild and severe disability. Having one chronic disease was marginally associated with sense of mastery, but having two or more chronic diseases did not add explanatory value.

\section{Change in mastery}

The correlations between baseline and follow-up mastery were 0.55 and 0.62 in the early and recent cohort, respectively. These correlation sizes show that there is substantial, but certainly not complete stability over time. On average, mastery did not change in the 3-year interval (average change +0.06 and -0.14 in the early and recent cohorts, neither of these significantly different from 0). A cohort difference in change in mastery was not apparent either $(F(\mathrm{df})=1.46(1), p=0.23)$.

\section{Explanatory factors of change in mastery}

In the combined sample, the model including baseline mastery and all potentially explanatory factors explained $23.6 \%(F(\mathrm{df})=38.2(13), p<0.001)$ of the total variance in change in mastery, calculated as the difference score of follow-up, $\mathrm{T}_{2}$, minus baseline, $\mathrm{T}_{1}$ (Table 2, last two columns). Regression to the mean was apparent from the inverse association of baseline mastery with change in mastery, indicating that those with a lower level of mastery were more likely to increase their mastery over 3 years' time than those with higher levels. Therefore, baseline mastery was included in all subsequent models examining

Table 2 Explanatory factors for baseline mastery and change in mastery, full model

\begin{tabular}{|c|c|c|c|c|}
\hline & \multicolumn{2}{|l|}{ Baseline mastery $^{\mathrm{a}}$} & \multicolumn{2}{|l|}{ Change in mastery ${ }^{\mathrm{b}}$} \\
\hline & $\begin{array}{l}\text { Standardised Beta } \\
\text { coefficient }\end{array}$ & $p$-value & $\begin{array}{l}\text { Standardised Beta } \\
\text { coefficient }\end{array}$ & $p$-value \\
\hline Baseline mastery (one point higher) & - & - & -0.52 & $<0.001$ \\
\hline Cohort (recent vs. early) & 0.05 & 0.05 & -0.01 & 0.60 \\
\hline Age (1 year higher) & -0.03 & 0.29 & -0.02 & 0.56 \\
\hline Gender (female vs. male) & -0.05 & 0.06 & -0.03 & 0.27 \\
\hline Education (one point higher) & 0.02 & 0.33 & 0.08 & 0.001 \\
\hline Partner (yes vs. no) & 0.05 & 0.05 & 0.02 & 0.40 \\
\hline Paid work (yes vs. no) & 0.05 & 0.04 & 0.03 & 0.27 \\
\hline \multicolumn{5}{|l|}{ Somatic diseases } \\
\hline One & -0.04 & 0.09 & -0.03 & 0.18 \\
\hline Two or more & -0.04 & 0.15 & -0.05 & 0.03 \\
\hline Subthreshold depression (yes vs. no) & -0.28 & $<0.001$ & -0.08 & 0.001 \\
\hline Cognitive impairment (yes vs. no) & -0.08 & $<0.001$ & -0.02 & 0.44 \\
\hline \multicolumn{5}{|l|}{ Disability longer than 3 months } \\
\hline Mild & -0.07 & 0.01 & -0.06 & 0.04 \\
\hline Severe & -0.07 & 0.01 & 0.03 & 0.29 \\
\hline
\end{tabular}

${ }^{a}$ Multivariable regression model with the continuous baseline score of mastery as the dependent variable

b Multivariable regression model with the continuous change score of mastery $\left(=T_{2}\right.$ score $-T_{1}$ score $)$ as the dependent variable 
Table 3 Specific conditions: direct effect on change in mastery ${ }^{\mathrm{a}}$ and interaction with cohort, each specific condition in a separate model ${ }^{\mathrm{b}}$

${ }^{\text {a }}$ Change in mastery $=$

$\mathrm{T}_{2}$ score $-\mathrm{T}_{1}$ score

b Each model adjusted for baseline mastery, age, sex, education, and somatic and mental comorbidity (multivariable regression models)

\begin{tabular}{lccl}
\hline & $\begin{array}{l}\text { Unstandardised } \\
\text { B coefficient }\end{array}$ & $p$-value & $\begin{array}{l}\text { Model improvement } \\
\text { with interaction } \\
\text { condition * cohort ( } p \text {-value) }\end{array}$ \\
\hline Heart disease & 0.13 & 0.55 & 0.02 \\
Peripheral artery disease & 0.05 & 0.87 & 0.18 \\
Stroke & -0.76 & 0.12 & 0.64 \\
Diabetes & 0.07 & 0.82 & 0.21 \\
Chronic lung disease & -0.43 & 0.08 & 0.32 \\
Cancer & -0.18 & 0.50 & 0.61 \\
Arthritis & -0.18 & 0.26 & 0.26 \\
Subthreshold depression & -0.89 & $<0.001$ & 0.68 \\
Cognitive impairment & -0.24 & 0.34 & 0.03 \\
Disability longer than 3 months & & & \\
Mild & -0.41 & 0.03 & 0.52 \\
Severe & 0.29 & 0.32 & 0.05 \\
\hline
\end{tabular}

explanatory factors of change in mastery to account for regression to the mean.

No cohort differences were apparent in rate of change in mastery. From the socio-demographic variables, only education was significantly associated with change in mastery, such that a higher level of education was associated with a more positive change. From the health variables, an increase in mastery was negatively associated with having somatic diseases, with mild (but not severe) disability, and with subthreshold depression at baseline. No association was found for cognitive impairment and severe disability.

\section{Change in mastery for specific conditions}

From the previous analysis, it is inferred that education should be included as a confounder in subsequent modelling. In addition, comorbidity of both somatic and mental conditions as well as disability may act as confounders. Therefore, each of the models examining change in mastery subsequent to a specific chronic disease include these variables as confounders, in addition to baseline mastery, age and sex (Table 3).
Subthreshold depression turned out to be the only condition directly and substantially associated with change in mastery: those with subthreshold depression were more likely to experience a decrease in mastery. Borderline associations were found for chronic lung disease $(p=0.08)$ and mild disability $(p=0.06)$, both in the same direction. Although the regression coefficient for stroke was substantial, it did not reach significance $(p=0.12)$ most likely due to the small number of participants with a stroke.

Cohort differences in change in mastery subsequent to having a disease were observed for heart disease, cognitive impairment, and severe disability, with interaction coefficients having respective $p$-values of $0.02,0.03$, and 0.06 . Stratified analyses by cohort (Table 4) showed that participants with a heart disease in the recent cohort were likely to experience an increase in mastery, whereas their counterparts in the early cohort did not experience a significant change. For cognitive impairment, however, a reversed pattern was observed: participants with cognitive impairment in the recent cohort experienced a decrease in mastery, whereas again no significant change was seen in the early cohort. For severe disability, in neither cohort a
Table 4 Specific conditions with interaction effects: association with change in mastery in early and recent cohort, adjusted models

\begin{tabular}{|c|c|c|c|c|}
\hline & \multicolumn{2}{|c|}{ Cohort $1928-1937$ in $1992-1993$} & \multicolumn{2}{|c|}{ Cohort $1938-1947$ in $2002-2003$} \\
\hline & $\begin{array}{l}\text { Unstandardised } \\
\text { B coefficient }\end{array}$ & $p$-value & $\begin{array}{l}\text { Unstandardised } \\
\text { B coefficient }\end{array}$ & $p$-value \\
\hline Heart disease & -0.34 & 0.24 & 0.67 & 0.03 \\
\hline Cognitive impairment & 0.37 & 0.32 & -0.74 & 0.03 \\
\hline \multicolumn{5}{|l|}{$\begin{array}{l}\text { Disability longer } \\
\text { than } 3 \text { months }\end{array}$} \\
\hline Severe & 0.54 & 0.16 & -0.37 & 0.24 \\
\hline
\end{tabular}


significant change was seen, although the regression coefficients had opposite signs.

\section{Discussion}

The aim of this study was to examine how middle-aged individuals' adaptation to a range of health problems changes over time. It was hypothesised that more recent cohorts differ from earlier cohorts in how they adapt to health problems. Using sense of mastery as the measure of adaptation, it was found that early and recent cohorts did not differ in sense of mastery, although level of education and gainful employment in the recent cohort had substantially increased, and-like in earlier studies (e.g. Cairney and Krause 2008; Slagsvold and Sorensen 2008) - these variables proved to be positively correlated with sense of mastery. Thus, in order to reach the same average in spite of more favourable socio-economic circumstances, the sense of mastery in the recent cohort must be lower in certain subgroups. Indeed, middle-aged individuals having subthreshold depression, disability and one somatic disease had a lower sense of mastery, and the size of these subgroups increased between 1992-1993 and 2002-2003. We showed, moreover, that those participants from the recent cohort who were in good (mental) health had a higher sense of mastery than the (mentally) healthy in the early cohort. This corresponds to the expectation that more recent cohorts have better mastery, perhaps because of their improved life course conditions. However, this better mastery was only apparent as long as they did not face health declines.

When comparing the explanatory models of baseline mastery and 3-year change in mastery, the socio-demographic variables appeared to have different explanatory value. Whereas in the baseline model education was not, but gender, having paid work, and partner status were significant, in the change model, education was the only significant explanatory variable among the socio-demographic variables. Ancillary analysis shows that gender and having paid work were associated with education: the more highly educated were more likely to be male and to be gainfully employed in this age group. Thus, education and employment status may have some overlap in explanatory power.

With respect to health variables, the baseline and change models were in agreement regarding the explanatory value of subthreshold depression, and the greater explanatory value of mild than of severe disability. The latter may seem counterintuitive, but might be explained by the inclusion of other health conditions into the model. Indeed, in a bivariate model, there was a graded association between extent of disability and mastery. Furthermore, while in the baseline model having one somatic disease, but not having two or more diseases, showed some (marginal) association with mastery, in the change model only having two or more diseases had significant explanatory value. A tentative explanation may be that over time, having complex health conditions such as two or more diseases is more detrimental to one's sense of mastery than just having one disease (regardless of the specific disease).

In subjects with specific conditions such as subthreshold depression, mild disability, chronic lung disease and stroke, sense of mastery decreased over time, and again the prevalence of these specific conditions increased between 1992-1993 and 2002-2003. Various studies have reported associations of depressive symptoms and disability with sense of mastery (e.g. Jang et al. 2009; Menec et al. 1999). However, our study showed that even controlling for the effects of depression and disability, some effects were maintained for chronic lung disease and stroke. A tentative explanation for the remaining effect of chronic lung disease is that this disease is characterised by an unpredictable and episodic course (Rolland 1987). This characteristic makes it difficult for patients to make adequate adjustments to the continually changing demands of the situation. This may be detrimental to their sense of mastery. Stroke, however, is characterised by a rather predictable course, once the acute effects have been managed. However, the experience that rehabilitation is not fully achieved may affect the sense of mastery of stroke patients. Moreover, a stroke may lead to changes in personality, which in turn may affect the sense of mastery (Stone et al. 2004).

Cohort differences in adaptation to illness were seen for heart disease and cognitive impairment, with opposite effects. In individuals with heart disease in the recent cohort, sense of mastery increased over time, whereas in individuals with cognitive impairment, sense of mastery decreased over time. In the early cohort, no significant changes over time were observed in these individuals. In the next paragraphs, these findings are discussed one by one.

Cognitive impairment showed a strong, direct association with baseline mastery. With change in mastery, cognitive impairment showed an association that corresponded to our hypothesis that in the recent cohort, poor health conditions are more detrimental to one's sense of mastery than in the early cohort. It is notable that this differential association becomes apparent in cognitive impairment. This may not so much be explained by cohort characteristics, as the overall level of education-a typical cohort characteristic-rose substantially. Instead, this may be explained by period effects. In the decade since the early 1990s, our society has become more and more an information society, where adequate cognitive functions are indispensable. Nevertheless, ageing-related declines in functions are not delayed, and may come at a relatively early age for some. For these individuals, the increasing 
appeal on cognitive functions, e.g. by the expansion of internet use and the increasing focus on individual choice in our society (Mikels et al. 2009), may be confusing and may confront them with their limitations more than used to be the case for earlier generations. Moreover, recent findings suggests that in the general population since the 1980s, the fear of dementia has grown as opposed to the fear of somatic diseases such as cancer (Borland et al. 1994; Anderson et al. 2009).

An intriguing finding was that in the recent cohort, mastery increased in individuals with heart disease. For one part, in middle-aged persons heart disease is predominantly myocardial infarction. When this is followed by rehabilitation, there need not be further long-term consequences. However, this does not explain the cohort difference observed. This difference may again be explained by period factors. The medical care of heart disease has improved considerably since the early 1990s. Prevention of heart disease has improved, e.g. by the decrease in number of smokers and the increasingly wide-spread intake of cholesterol lowering medications (Crimmins 2004; Kuuslasmaa et al. 2000). Treatment of heart disease has become more fine-tuned, amongst others by better medications, but also by better disease management, where patients are encouraged to control their life style and prevent recurrence. In contrast, for other diseases medical care may not have made such progress so far.

In this study, subthreshold depression and functional limitations were accounted for in all chronic disease-specific models. However, it may be argued that these health conditions are intermediary variables between some chronic diseases and mastery. If this would be the case, to include them as confounders would cause some models to be overadjusted, and the effect of some chronic conditions would have been underestimated.

In interpreting the findings of this study, some further caveats are in place. First, although the aim of this study was to address adaptation to disease, the operational definition of adaptation as a positive change in mastery may not be sufficiently adequate. Whereas it is assumed that a higher mastery implies better adaptation, it is true that in some cases a lower mastery actually reflects successful adaptation. This might be the case when a chronic condition prevents the performance of activities needed to change one's situation, so that it seems better to adjust one's ambitions (Brandtstädter 2009). To address this type of adaptation, more specific measures are needed. Second, all measures of health conditions except cognitive impairment were based on self-reports. This may be suitable for depression and disability, but may be less satisfactory for chronic diseases. However, in a comparison of self-reported diseases with those obtained from the registers of the participants' general practitioners, the agreement was shown to be satisfactory with high kappa's $(>0.60)$ for heart disease, diabetes, chronic lung disease, and cancer (Kriegsman et al. 1996). For the other diseases, somewhat lower kappa's were found and misclassification may have diluted the results. A further caveat regarding the use of self-reports is that reporting practices may have changed from one cohort to the other, thus leading to differences between prevalences and perhaps even between associations with change in mastery across cohorts. Third, in this age group, the prevalence of several diseases is still quite low, thus limiting the power to detect meaningful associations. Fourth, the response rates in the two cohorts was rather low (around 60\%), and lower in the recent than in the early cohort. This may have caused the recent cohort to consist of healthier participants. However, from the comparison of baseline characteristics this appeared not to be the case. In fact, the prevalence of most somatic and mental conditions was higher in the recent cohort. Because of the longitudinal nature of this study, the main threat to its validity is selective attrition. It is true that in comparison to the surviving drop-outs, the continuing participants were more often highly educated, more often had a partner, less often had subthreshold depression, cognitive impairment or severe disability, and also had a higher baseline mastery, but they were no different in terms of age, gender, gainful employment, and somatic conditions. It is difficult to judge how this selectivity could have affected the findings, and even, if it would affect the findings at all (Kempen and Van Sonderen 2002). A fifth and final caveat pertains to our analytic approach. Except for mastery itself, for all variables only baseline assessments were included in our regression models. Thus, the problem of disentangling cause and effect is reduced, because the chronological sequence is clear. Moreover, chronic diseases are by definition permanent, as they cannot be cured. Indeed, theoretically, it is possible that a decline in mastery would be the cause of a chronic condition, but this does not seem likely. Nevertheless, the problem of attributing causality cannot be easily solved when just two time points are available. Further research to replicate and expand our findings might use more than two time points and apply longitudinal analyses such as latent change models.

In conclusion, our findings indicate that the sense of mastery in recent cohorts is better than in earlier cohorts, provided they have not experienced health declines. Several health problems were associated with declines in mastery over time in both cohorts, and cognitive impairment was associated with mastery decline only in the recent cohort. Individuals with heart disease, in contrast, experienced increases in mastery over 3 years only in the recent cohort. This latter finding suggests that disease management programmes can in fact be designed such that the course of a disease does not imply deteriorating 
feelings of mastery (Lorig and Holman 2003). For diseases other than heart disease, there seems to be much room for improvement in disease management. Moreover, multimorbidity needs special attention. If a disease leads to depression and disability, interventions need to reduce these consequences. In all, the findings from this study may help to focus interventions in specific patient groups.

Acknowledgments This study is based on data collected in the context of the Longitudinal Aging Study Amsterdam (LASA), which is funded largely by the Ministry of Welfare, Health and Sports of the Netherlands.

Open Access This article is distributed under the terms of the Creative Commons Attribution Noncommercial License which permits any noncommercial use, distribution, and reproduction in any medium, provided the original author(s) and source are credited.

\section{References}

Anderson LA, Day KL, Beard RL, Reed PS, Wu B (2009) The public's perceptions about cognitive health and Alzheimer's disease among the U.S. population: a national review. Gerontologist 49:3-11

Beekman ATF, Deeg DJH, Van Limbeek J, Braam AW, De Vries MZ (1997) Criterion Validity of the Center for Epidemiologic Studies Depression scale (CES-D): results from a communitybased sample of older subjects in the Netherlands. Psychol Med 27:231-235

Bisschop MI, Kriegsman DMW, Beekman ATF, Deeg DJH (2004) Chronic diseases and depression: the modifying role of psychosocial resources. Soc Sci Med 57:187-194

Borland R, Donaghue N, Hill D (1994) Illnesses that Australians most feared in 1986 and 1993. Aust J Public Health 18:366-369

Brandtstädter J (2009) Goal pursuit and goal adjustment: selfregulation and intentional self-development in changing developmental contexts. Adv Life Course Res 14:52-62

Broese van Groenou MI, Deeg DJH (2010) Formal and informal social participation of the 'young-old' in The Netherlands in 1992 and 2002. Ageing Soc 30:445-465

Cairney J, Krause N (2008) Negative life events and age-related decline in mastery: are older adults more vulnerable to the control-eroding effects of distress? J Gerontol Soc Sci 63B:S162-S170

Chipperfield JG, Campbell DW, Perry RP (2004) Stability in perceived control: implications for health among very old community-dwelling adults. J Aging Health 16:116-147

Crimmins EM (2004) Trends in the health of the elderly. Annu Rev Public Health 25:79-98

Deeg DJH, Knipscheer CPM, Van Tilburg W (eds) (1993) Autonomy and well-being in the aging population: concepts and design of the Longitudinal Aging Study Amsterdam. NIG Trend studies No. 7. Netherlands Institute of Gerontology, Bunnik, the Netherlands

Deeg DJH, Van Tilburg T, Smit JH, De Leeuw ED (2002) Attrition in the Longitudinal Aging Study Amsterdam: the effect of differential inclusion in side studies. J Clin Epidemiol 55:319-328

Femia EE, Zarit SH, Johansson B (1997) Predicting change in activities of daily living: a longitudinal study of the oldest old in Sweden. J Gerontol Psychol Sci 52B:P294-P302

Folstein MF, Folstein SE, McHugh PR (1975) Mini-mental state: a practical method for grading the cognitive state of patients for the clinician. J Psychiatr Res 12:189-198
Gadalla TM (2009) Sense of mastery, social support, and health in elderly Canadians. J Aging Health 21:582-595

Jang Y, Chiriboga DA, Lee J, Cho S (2009) Determinants of a sense of mastery in Korean American elders: a longitudinal assessment. Aging Mental Health 13:99-105

Kempen GIJM, Van Sonderen E (2002) Psychological attributes and changes in disability among low-functioning older persons: does attrition affect the outcomes? J Clin Epidemiol 55:224-229

Kriegsman DMW, Penninx BWJH, Van Eijk JTM, Boeke AJP, Deeg DJH (1996) Self-reports and general practitioner information on the presence of chronic diseases in community-dwelling elderly. A study on the accuracy of patients' self-reports and on determinants of inaccuracy. J Clin Epidemiol 49:1407-1417

Kuuslasmaa K, Tunstall-Pedoe H, Dobson A, Fortmann S, Sans S, Tolonen H, Evans A, Ferrario M, Tuomilehto J, for the WHO MONICA project (2000) Estimation of contribution of changes in classic risk factors to trends in coronary-event rates across the WHO MONICA project populations. Lancet 355:675-687

Lorig KR, Holman H (2003) Self-management education: history, definition, outcomes, and mechanisms. Ann Behav Med 26:1-7

Mackenbach JP, Borsboom GJJM, Nusselder WJ, Looman CWN, Schrijvers CTM (2001) Determinants of levels and changes of physical functioning in chronically ill persons: results from the GLOBE study. J Epidemiol Community Health 55:631-638

Menec VH, Chipperfield JG, Perry RP (1999) Self-perceptions of health: a prospective analysis of mortality, control, and health. J Gerontol Psychol Sci 54B:P85-P93

Mikels JA, Reed AE, Simon KI (2009) Older adults place lowe value on choice relative to young adults. J Gerontol Psychol Sci 64B: 443-446

Moos RH, Schaeffer JA (1984) The crisis of physical illness. An overview and conceptual approach. In: Moos RH (ed) Coping with physical illness 2: new perspectives. Plenum Medical Book Company, New York, pp 3-25

Pearlin LI, Schooler C (1978) The structure of coping. J Health Soc Behav 19:2-21

Pearlin LI, Menaghan EG, Lieberman MA, Mullan JT (1981) The stress process. J Health Soc Behav 22:337-356

Radloff LS (1977) The CES-D scale: a self-report depression scale for research in the general population. Appl Psychol Meas 1:385-401

Rodin J, Timko C (1991) Sense of control, aging, and health. In: Ory MG, Abeles RP (eds) Aging, health, and behavior. Sage, Thousand Oaks, CA, pp 174-206

Rolland JS (1987) Chronic illness and the life cycle: a conceptual framework. Fam Process 26:203-221

Rowe JW, Kahn RL (1997) Successful aging. Gerontologist 37: $433-440$

Slagsvold B, Sorensen A (2008) Age, education, and the gender gap in the sense of control. Int J Aging Hum Dev 67:25-42

Stone J, Townend E, Kwan J, Haga K, Dennis MS, Sharpe M (2004) Personality change after stroke: some preliminary observations. J Neurol Neurosurg Psychiatr 75:1708-1713

Tombaugh TN, McIntyre NJ (1992) The mini-mental state examination: a comprehensive review. J Am Geriatr Soc 40:922-935

Van Oyen H, Van der Heyden J, Perenboom R, Jagger C (2006) Monitoring population disability: evaluation of a new Global Activity Limitation Indicator (GALI). Soz Praventivmed 51: 153-161

Wallhagen MI, Strawbridge WJ, Kaplan GA, Cohen RD (1994) Impact of internal health locus of control on health outcomes for older men and women-a longitudinal perspective. Gerontologist 34:299-306

Wolinsky FD, Wyrwich KW, Babu AN, Kroenke K, Tierney WM (2003) Age, aging, and the sense of control among older adults: a longitudinal reconsideration. J Gerontol Soc Sci 58B:S212-S220 